\title{
MÉTODOS FÍSICOS PARA CONTROLE DA INCRUSTAÇÃO POR CIRRIPEDIA (CRUSTACEA: MAXILLOPODA) EM SUBSTRATOS ARTIFICIAIS: UM ESTUDO BIBLIOMÉTRICO
}

\author{
Marinho, M.S. ${ }^{1,2}$; Campos, J.M.P. ${ }^{1,2}$; Silva, A.K.P. ${ }^{1,3}$, Fernandes, M.L.B. ${ }^{1,4}$ \& Gouveia, R.L. ${ }^{1}$ \\ ${ }^{1}$ Instituto Avançado de Tecnologia e Inovação (IATI). \\ ${ }^{2}$ Universidade Federal de Pernambuco (UFPE), Campus Recife, Laboratório de Bentos. \\ ${ }^{3}$ Universidade de Pernambuco (UPE), Campus Benfica, Laboratório de Estudos Ambientais. \\ ${ }^{4}$ Universidade de Pernambuco (UPE), Campus Mata Norte, Laboratório de Estudos Ambientais. \\ *Autor correspondente: marlanemarinho@yahoo.com.br
}

\begin{abstract}
A Incrustação biológica em determinadas estruturas artificiais pode ser considerada como crescimento prejudicial da comunidade marinha em superfícies submersas. No caso das cracas, a competição por um local para se fixar é extremamente acentuada, podendo causar problema notório, uma vez que são espécies oportunistas e sua colonização gregária em superfícies sólidas danifica suas estruturas. Os biocidas são eficazes ao seu controle, mas as suas aplicações são restritas ou proibidas devido a preocupações ambientais. No presente trabalho foi realizado um estudo bibliométrico sobre métodos físicos para controle de cracas que se desenvolvem em estruturas artificiais submersas, utilizando a base de dados Scopus, sendo realizado o levantamento dos artigos por indicadores controlados. Pesquisas publicadas entre 2005 e 2014 relataram que a utilização de ultrassom e radiação ultravioleta são os métodos físicos mais estudados para o controle da fauna Balanomorpha em substratos artificiais submersos em ambientes marinhos. Dos dez artigos publicados nesse período, seis foram de autoria da Universidade Nacional de Singapura e três da Universidade de Hong Kong no Sudoeste Asiático, revelando este ser um continente onde as pesquisas sobre os métodos físicos no controle do fouling se encontra crescente. Destaca-se que o uso do ultrassom pode afetar o assentamento, a viabilidade e o comportamento das cracas, se mostrando promissor na prevenção das incrustações, inviabilizando o uso de soluções que não são ambientalmente seguras. Esta pesquisa é financiada com recursos do Programa de P\&D regulado pela Aneel.
\end{abstract}

Palavras-chave: controle do fouling; antifouling; eficiência ecológica. 